\title{
PENGARUH PENGERINGAN PREPARAT BAKTERI \\ TAHAN ASAM PADA INKUBATOR TERHADAP \\ HASIL PEMERIKSAAN MIKROSKOPIK
}

*Nining Kurniati, *Shufiyani

\begin{abstract}
Abstrak
Target utama pengedalian penyakit tuberculosis paru (TB) adalah menemukan pasien TB menular (BTA positif) dan menyembuhkan penyakitnya. Dengan memprioritaskan pada penemuan pasien TB dengan BTA positif, maka laboratorium merupakan kunci utama dalam mendiagnosis pasien TB. Pemeriksaan mikroskopik sediaan dahak merupakan salah satu cara yang paling efisien untuk mengidentifikasi penderita TB. Penderita dengan sediaan positif, sepuluh kali lebih infeksius dibandingkan dengan penderita dengan sediaan negatif. ${ }^{(9)}$ Berdasarkan hasil pemeriksaan data pemeriksaan makroskopik, mikroskopik dan kultur maka didapatkan hasil penelitian sebagai berikut, 1)Tidak ada pengaruh pada pengeringan pada suhu kamar dan suhu inkubator. 2) Gambaran hasil preparat BTA pada pengeringan suhu $20^{\circ} \mathrm{C}$ (suhu kamar) dan suhu incubator $\left(50^{\circ} \mathrm{C}, 60^{\circ} \mathrm{C}\right.$ dan $\left.70^{\circ} \mathrm{C}\right)$, untuk sampel positif 1 didapatkan hasil $100 \%$ hasil pemeriksaan mikroskopik positif 1, dan sampel positif 3 didapatkan hasil $100 \%$ pemeriksaan mikrskop positif 3. 3)Gambaran stabilitas hasil preparat BTA pada pengeringan suhu $20^{\circ} \mathrm{C}$ (suhu kamar) dan suhu incubator $\left(50^{\circ} \mathrm{C}, 60^{\circ} \mathrm{C}\right.$ dan $70^{\circ} \mathrm{C}$ ) selama 3 minggu $100 \%$ hasilnya sama menunjukan preparat tersebut stabil.
\end{abstract}

Kata Kunci: BTA, Preparat, TB.

*Dosen Jurusan Analis Kesehatan Poltekkes Banten

\section{Pendahuluan}

\begin{tabular}{|c|c|}
\hline \begin{tabular}{c}
\multicolumn{2}{c}{ Target utama pengedalian } \\
penyakit tuberculosis paru $(\mathrm{TB})$
\end{tabular} & $\begin{array}{l}\text { strategi DOTS, yaitu penegakan } \\
\text { diagnosis menggunakan pemeriksaan }\end{array}$ \\
\hline menemukan & mikroskopik. \\
\hline menular & mikrsokopik BTA dari specimen \\
\hline penyakitnya. & sputum memegang peran penting \\
\hline memprioritaskan & diagnosis \\
\hline penemuan pasien TB dengan BTA & pemantauan \\
\hline laboratorium & Tuberkulosis \\
\hline merupakan kunci utama dalam & kegiatan yang baik diperlukan untuk \\
\hline mendiagnosis pasien TB. Hal & mendapatkan hasil \\
\hline gaskan & ulal \\
\hline
\end{tabular}


sputum, pemilihan bahan sputum yang akan diperiksa, pembuatan sediaan apus sputum, teknik pewarnaan dan alat-alat atau bahan/reagen harus diperhatikan kualitasnya. ${ }^{(1)}$

Terkadang setelah pewarnaan hasil pembacaan sediaan BTA positif akan berubah setelah penyimpanan lebih dari 3 bulan, BTA positif berubah menjadi negatif pada saat akan melakukan cross-check. Pemantapan mutu sediaan mikroskopik BTA untuk mendiagnosis tuberculosis mengandalkan mikroskopik sediaan dahak. Pemeliharaan atas mutu mikroskopik sangat penting untuk memastikan layanan pemeriksaan Program TB Nasional yang tepat dan terpercaya. $^{(2)}$

Seiring dengan tingkat kesadaran masyarakat untuk memeriksakan diri pada tempat pelayanan kesehatan, termasuk Puskesmas, jumlah slide yang akan diperiksa oleh laboratorium puskesmas tentu akan semakin banyak dan memerlukan kesigapan petugas laboratorium. Namun salah satu proses dalam pemeriksaan dahak secara mikroskopik, yaitu pengeringan slide pada suhu ruangan sesudah pewarnaan Ziehl Neelsen, memakan waktu yang cukup lama sehingga seorang Analis Kesehatan memerlukan waktu yang lama pula untuk memberikan informasi hasil pemeriksaan dahak kepada dokter. ${ }^{(3)}$

Oleh sebab itu akan dilakukan penelitian mengenai pengaruh pengeringan preparat BTA dengan menggunakan suhu incubator terhadap hasil pemeriksaan mikroskopik.

\section{Metode Penelitian}

\section{Pemeriksaan Laboratorium}

\section{Tuberkulosis Paru}

Pemeriksaan mikroskopik dahak :

Pemeriksaan mikroskopik sediaan dahak merupakan salah satu cara yang paling efisien untuk mengidentifikasi penderita TB. Penderita dengan sediaan positif, sepuluh kali lebih infeksius dibandingkan dengan penderita dengan sediaan negatif. ${ }^{(9)}$

Fungsi pemeriksaan mikroskopis dahak :

1. Menegakkan diagnosis TB 
2. Menentukan

tingkat penularan

3. Memantau kemajuan pengobatan

4. Menentukan terjadinya kegagalan pada akhir pengobatan

Pengumpulan dahak

Dibutuhkan 3 spesimen dahak untuk menegakkan diagnosis TB, untuk kenyamanan penderita, pengumpulan dahak dilakukan dengan prinsip sewaktu-pagisewaktu.

Sewaktu Hari Ke-1: Kumpulkan specimen pertama pada saat penderita berkunjung ke klinik. Beri pot dahak pada saat penderita pulang untuk keperluan pengumpulan dahak pada pagi hari berikutnya.

Pagi Hari Ke-2: Penderita mengumpulkan dahak pada pagi hari kedua segera setelah bangun tidur (specimen kedua) dan bawa ke klinik.

Sewaktu Hari Ke-2: kumpulkan spesimen ketiga di klinik pada hari kedua dengan membawa dahak pagi. ${ }^{(9)}$
Cara mengumpulkan spesimen:

Jangan berdiri di depan penderita pada saat pengumpulan spesimen. Beri petunjuk penderia untuk: 1. Tarik nafas dalamdalam 2 sampai 3 kali dan setiap kali hembuskan nafas dengan kuat. 2. Batukkan dengan keras dari dalam dada. 3. Letakkan pot yang sudah dibuka dekat dengan mulut dan keluarkan dahak ke dalam pot. 4. Tutup pot dengan ketat dengan cara memutar tutupnya. ${ }^{(9)}$

Kualitas spesimen yang baik adalah yang mukoid, purulen. Kualitas spesimen yang jelek adalah spesimen yang encer dan seperti air atau sebagian besar terdiri dari gelembunggelembung. ${ }^{(9)}$

Cara Pembuatan Sediaan BTA dan Pewarnaan sediaan dahak (Ziehl Nelseen):

a. Pemberian nomor sediaan Pilih kaca sediaan yang baru, bersih, bebas-minyak, tanpa goresan dan bebas dari sidik jari. Pastikan nomor tiap sediaan sesuai dengan nomor pada wadah dahak. Tulis nomor 
urutan tahun dan noor spesimen dahak pada ujung kaca sediaan.

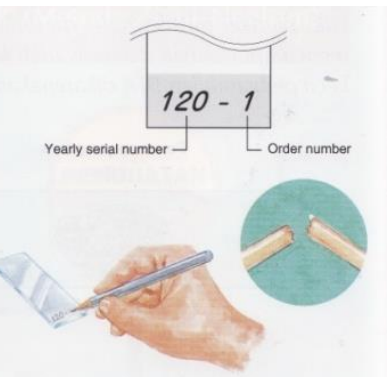

Gambar 2.3 Pemberian nomor sediaan $^{(10)}$

a. Pembuatan sediaan dahak

Gunakan lidi/batang bambu yang dipatahkan untuk mengambil dahak, pilih dan ambil dahak yang purulen/kental kuning kehijauan. Ratakan dahak pada kaca sediaan, oleskan dengan pola melingkar kecil-kecil sampai sediaan berbentuk oval dengan ukuran lebar $1-2 \mathrm{~cm}$ dan panjang 2-3cm. Sengkelit/ose dengan diameter 3 mm dapat juga digunakan untuk memindah dahak untuk membuat suatu olesan.

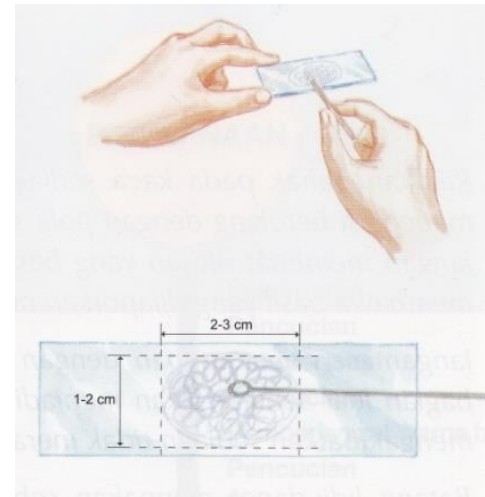

Gambar 2.4 Pembuatan sediaan

$$
\text { dahak }^{(10)}
$$

b. Pengeringan dan fiksasi sediaan dahak

Keringkan sediaan dahak pada suhu kamar. Jangan dikeringkan dibawah panas matahari atau di atas api, setelah sediaan benar-benar kering, pegang sediaan memakai pinset/penjepit dengan permukaan sediaan dahak menghadap ke atas. Lewatkan sediaan di atas api 2-3 kali, sekitar 2-3 detik. Jangan memanaskan sediaan terlalu lama atau mendiamkannya di atas api, karena sediaan akan hangus. 


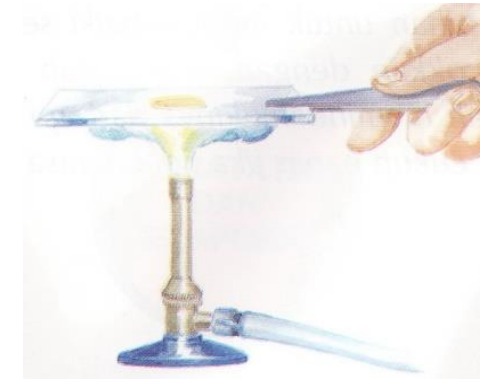

Gambar 2.5 Pengeringan dan

fiksasi sedaiaan dahak ${ }^{(10)}$

c. Penyusunan sediaan dahak

Sediaan disusun menurut nomor seri pada rak pewarnaan dengan permukaan sediaan menghadap ke atas. Beri jarak yang cukup antar sediaan untuk mencegah pemindahan bahan dan cairan mengalir dari kaca sediaan satu ke lainnya.

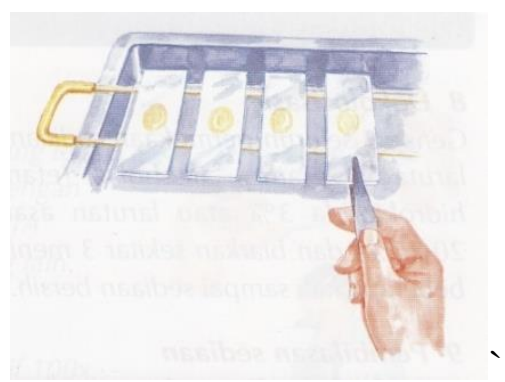

Gambar 2.6 Penyusunan sediaan di rak pewarnaan ${ }^{(10)}$

d. Pewarnaan dengan larutan karbol fuchsin

Genangi seluruh permukaan sediaan dengan larutan karbol fuchsin, jika cairan karbol fuchsin mengalir, tambahkan lebih banyak untuk menutupi seluruh kaca sediaan.

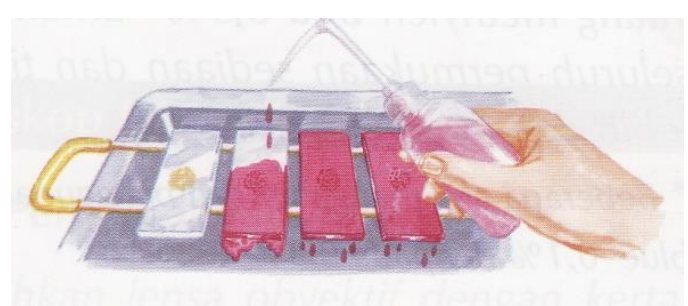

Gambar 2.7 Pewarnaan dengan larutan karbol fuchsin ${ }^{(10)}$

e. Pemanasan sediaan

Panaskan sediann sampai timbul uap. Jangan didihkan atau membiarkan sediaan kering, karena akan timbul kristal pada sediaan. Biarkan 5 menit dan jangan biarkan larutan mengering.

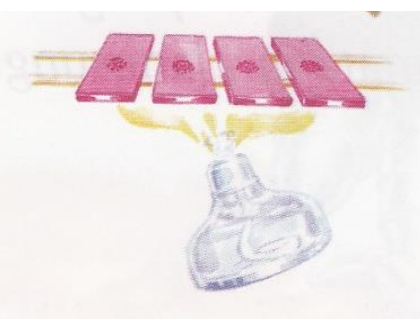

\section{Gambar 2.8 Pemanasan sediaan ${ }^{(10)}$}

f. Pembilasan sediaan Miringkan kaca sediaan untuk mengalirkan kelebihan pewarna dan cuci cairan pewarnaan perlahan dengan air mengalir. Miringkan kaca sediaan untuk mengalirkan kelebihan air cucian. 


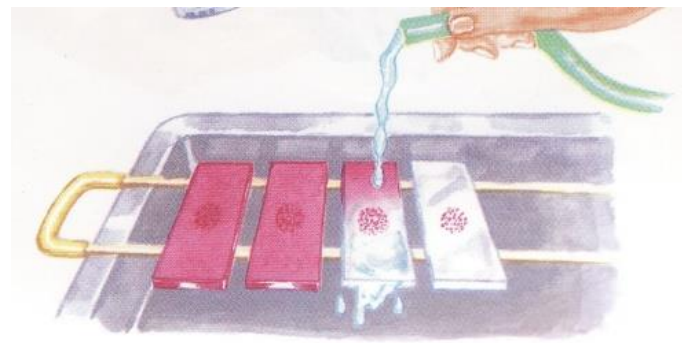

Gambar 2.9 Pembilasan sediaan ${ }^{(10)}$

g. Dekolorisasi

Genangi seluruh permukaan sediaan dengan larutan asam alkohol (etanol-asam hidroklorida $3 \%$ atau larutan asam sulfat 20-25\%) dan biarkan sekitar 3 menit. Ulangi beberapa kali sampai sediaan bersih.

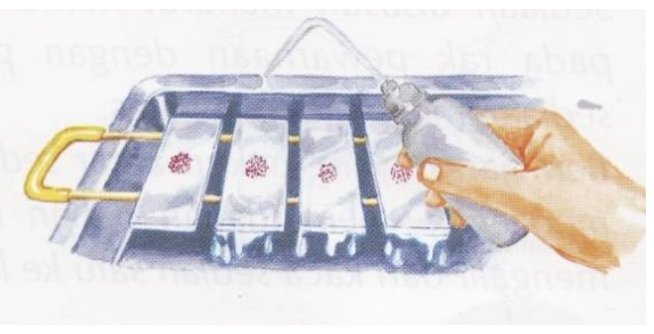

Gambar 2.10 Dekolorisasi ${ }^{(10)}$

h. Pembilasan sediaan

Cuci kaca sediaan dengan air mengalir perlahan dan miringkan untuk mengalirkan kelebihan air cucian.

i. Pewarnaan methylen biru Tuang methylen biru 0,3\% untuk menutupi seluruh permukaan sediaan dan tidak boleh lebih dari 30 detik.

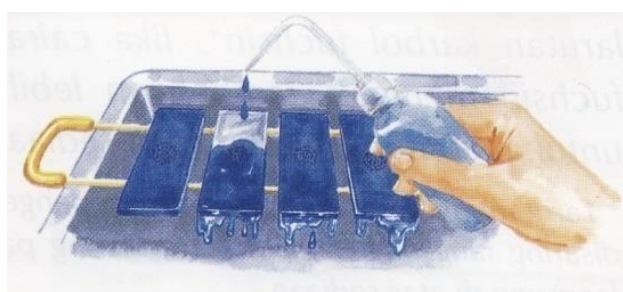

Gambar 2.11 Pewarnaan methylen

$$
\text { biru }^{(10)}
$$

j. Pembilasan sediaan Tuang larutan methylen biru $0,3 \%$ dan bilas sediaan dengan air yang mengalir perlahan.

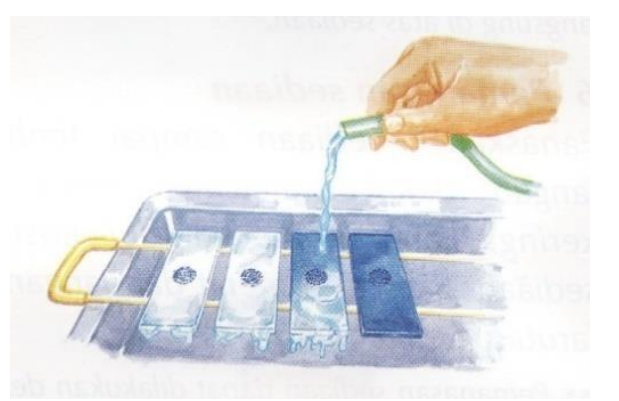

\section{Gambar 2.12 Pembilasan sediaan ${ }^{(10)}$}

k. Pengeringan sediaan yang telah diwarnai

Miringkan dan letakkan sediaan pada rak sediaan dan keringkan di udara.

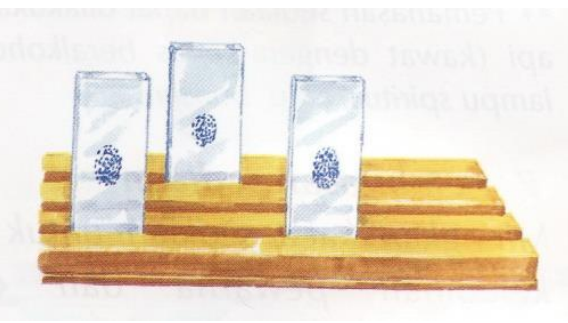

\section{Gambar 2.13 Pengeringan sediaan yang telah diwarnai ${ }^{(10)}$}




\section{HASIL DAN PEMBAHASAN}

Dilakukan

pembuatan

preparat dahak dari dua sampel BTA positif yaitu : BTA positif 1 dan

BTA positif 3, masing-masing 20 preparat BTA. Kemudian dilakukan pewarnaan dan pengeringan pada suhu kamar dan inkubator, pembagian sampel dapat dilihat pada tabel berikut ini :

Tabel 3.1 Sampel Preparat BTA

\begin{tabular}{|c|c|c|c|c|c|c|c|c|}
\hline & \multicolumn{4}{|c|}{ BTA positif 1} & \multicolumn{4}{|c|}{ BTA positif 3} \\
\hline & \multirow{2}{*}{$\begin{array}{l}\text { Suhu } \\
\text { kamar }\end{array}$} & \multicolumn{3}{|c|}{ Suhu Inkubator } & \multirow{2}{*}{$\begin{array}{l}\text { Suhu } \\
\text { kamar }\end{array}$} & \multicolumn{3}{|c|}{ Suhu Inkubator } \\
\hline & & $50^{\circ} \mathrm{C}$ & $60^{\circ} \mathrm{C}$ & $7^{\circ} \mathrm{C}$ & & $5^{\circ} \mathrm{C}$ & $60^{\circ} \mathrm{C}$ & $7^{\circ} \mathrm{C}$ \\
\hline \multirow{5}{*}{ 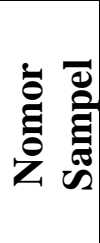 } & 1A1 & 1B1 & $1 \mathrm{C} 1$ & 1D1 & $3 \mathrm{~A} 1$ & $3 \mathrm{~B} 1$ & $3 \mathrm{C} 1$ & 3D1 \\
\hline & $1 \mathrm{~A} 2$ & $1 \mathrm{~B} 2$ & $1 \mathrm{C} 2$ & 1D2 & $3 \mathrm{~A} 2$ & $3 \mathrm{~B} 2$ & $3 \mathrm{C} 2$ & 3D2 \\
\hline & $1 \mathrm{~A} 3$ & $1 \mathrm{~B} 3$ & $1 \mathrm{C} 3$ & 1D3 & $3 \mathrm{~A} 3$ & $3 \mathrm{~B} 3$ & $3 \mathrm{C} 3$ & 3D3 \\
\hline & $1 \mathrm{~A} 4$ & 1B4 & $1 \mathrm{C} 4$ & 1D4 & $3 \mathrm{~A} 4$ & 3B4 & $3 \mathrm{C} 4$ & 3D4 \\
\hline & $1 \mathrm{~A} 5$ & 1B5 & $1 \mathrm{C5}$ & 1D5 & $3 \mathrm{~A} 5$ & $3 \mathrm{~B} 5$ & $3 \mathrm{C} 5$ & 3D5 \\
\hline
\end{tabular}

Dari data tersebut didapatkan

hasil pembuatan preparat BTA positif 1dan positif 3 pada suhu kamar, $50^{\circ} \mathrm{C}, 60^{\circ} \mathrm{C}$ dan $70^{\circ} \mathrm{C}$ masingmasing 5 preparat.

Tabel 3.2 Hasil Pemeriksaan Mikroskopik Preparat BTA

\begin{tabular}{|c|c|c|c|c|c|c|c|c|c|}
\hline No & Suhu & $\begin{array}{l}\text { Nomor } \\
\text { Sampel }\end{array}$ & $\begin{array}{c}\text { Jumlah } \\
\text { BTA }\end{array}$ & Hasil & No & Suhu & $\begin{array}{l}\text { Nomor } \\
\text { Sampel }\end{array}$ & $\begin{array}{c}\text { Jumlah } \\
\text { BTA }\end{array}$ & Hasil \\
\hline 1 & \multirow{5}{*}{$\begin{array}{l}\text { Suhu } \\
\text { kamar }\end{array}$} & $1 \mathrm{~A} 1$ & 78 & Positif 1 & 21 & \multirow{5}{*}{$\begin{array}{l}\text { Suhu } \\
\text { kamar }\end{array}$} & $3 \mathrm{~A} 1$ & $>1000$ & Positif 3 \\
\hline 2 & & $1 \mathrm{~A} 2$ & 68 & Positif 1 & 22 & & $3 \mathrm{~A} 2$ & $>1000$ & Positif 3 \\
\hline 3 & & $1 \mathrm{~A} 3$ & 82 & Positif 1 & 23 & & $3 \mathrm{~A} 3$ & $>1000$ & Positif 3 \\
\hline 4 & & $1 \mathrm{~A} 4$ & 81 & Positif 1 & 24 & & $3 \mathrm{~A} 4$ & $>1000$ & Positif 3 \\
\hline 5 & & $1 \mathrm{~A} 5$ & 76 & Positif 1 & 25 & & $3 \mathrm{~A} 5$ & $>1000$ & Positif 3 \\
\hline 6 & \multirow{5}{*}{$50^{\circ} \mathrm{C}$} & $1 \mathrm{~B} 1$ & 71 & Positif 1 & 26 & \multirow{5}{*}{$50^{\circ} \mathrm{C}$} & $3 \mathrm{~B} 1$ & $>1000$ & Positif 3 \\
\hline 7 & & $1 \mathrm{~B} 2$ & 67 & Positif 1 & 27 & & $3 \mathrm{~B} 2$ & $>1000$ & Positif 3 \\
\hline 8 & & 1B3 & 89 & Positif 1 & 28 & & $3 \mathrm{~B} 3$ & $>1000$ & Positif 3 \\
\hline 9 & & $1 \mathrm{~B} 4$ & 54 & Positif 1 & 29 & & $3 \mathrm{~B} 4$ & $>1000$ & Positif 3 \\
\hline 10 & & 1B5 & 67 & Positif 1 & 30 & & 3B5 & $>1000$ & Positif 3 \\
\hline 11 & \multirow{5}{*}{$60^{\circ} \mathrm{C}$} & $1 \mathrm{C} 1$ & 76 & Positif 1 & 31 & \multirow{5}{*}{$60^{\circ} \mathrm{C}$} & $3 \mathrm{C} 1$ & $>1000$ & Positif 3 \\
\hline 12 & & $1 \mathrm{C} 2$ & 78 & Positif 1 & 32 & & $3 \mathrm{C} 2$ & $>1000$ & Positif 3 \\
\hline 13 & & $1 \mathrm{C} 3$ & 87 & Positif 1 & 33 & & $3 \mathrm{C} 3$ & $>1000$ & Positif 3 \\
\hline 14 & & $1 \mathrm{C} 4$ & 73 & Positif 1 & 34 & & $3 \mathrm{C} 4$ & $>1000$ & Positif 3 \\
\hline 15 & & $1 \mathrm{C} 5$ & 63 & Positif 1 & 35 & & $3 \mathrm{C} 5$ & $>1000$ & Positif 3 \\
\hline
\end{tabular}




\begin{tabular}{|c|c|c|c|c|c|c|c|c|c|}
\hline 16 & \multirow{5}{*}{$70^{\circ} \mathrm{C}$} & 1D1 & 56 & Positif 1 & 36 & \multirow{5}{*}{$70^{\circ} \mathrm{C}$} & 3D1 & $>1000$ & Positif 3 \\
\hline 17 & & 1D2 & 76 & Positif 1 & 37 & & $3 \mathrm{D} 2$ & $>1000$ & Positif 3 \\
\hline 18 & & 1D3 & 46 & Positif 1 & 38 & & 3D3 & $>1000$ & Positif 3 \\
\hline 19 & & $1 \mathrm{D} 4$ & 74 & Positif 1 & 39 & & $3 \mathrm{D} 4$ & $>1000$ & Positif 3 \\
\hline 20 & & 1D5 & 65 & Positif 1 & 40 & & 3D5 & $>1000$ & Positif 3 \\
\hline
\end{tabular}

Didapatkan hasil pemeriksaan Setelah dilakukan mikroskopis dengan pengeringan pengeringan dengan berbagai suhu suhu kamar, $50^{\circ} \mathrm{C}, 60^{\circ} \mathrm{C}$ dan $70^{\circ} \mathrm{C}$. maka dilakukan uji stabilitas setiap Masing-masing pengeringan minggu selama 3 minggu, dapat mendapatkan hasil positif sesuai dilihat hasilnya pada tabel berikut ini dengan sampel awal.

Tabel 3.3 Hasil Pemeriksaan Stabilitas Preparat BTA

\begin{tabular}{|c|c|c|c|c|c|c|c|}
\hline \multirow[b]{2}{*}{ No } & \multirow[b]{2}{*}{ Suhu } & \multirow{2}{*}{$\begin{array}{l}\text { Nomor } \\
\text { Sampel }\end{array}$} & \multicolumn{3}{|c|}{ Hasil } & \multirow{2}{*}{$\begin{array}{c}\% \\
\text { Stabilitas }\end{array}$} & \multirow{2}{*}{$\begin{array}{l}\text { Rata- } \\
\text { rata \% }\end{array}$} \\
\hline & & & $\begin{array}{c}\text { Minggu } \\
\text { Ke-1 }\end{array}$ & $\begin{array}{c}\text { Minggu } \\
\text { Ke-2 }\end{array}$ & $\begin{array}{c}\text { Minggu } \\
\mathrm{Ke}-3\end{array}$ & & \\
\hline 1 & \multirow{5}{*}{$\begin{array}{l}\text { Suhu } \\
\text { kamar }\end{array}$} & $1 \mathrm{~A} 1$ & Positif 1 & Positif 1 & Positif 1 & $100 \%$ & \multirow{20}{*}{$100 \%$} \\
\hline 2 & & $1 \mathrm{~A} 2$ & Positif 1 & Positif 1 & Positif 1 & $100 \%$ & \\
\hline 3 & & $1 \mathrm{~A} 3$ & Positif 1 & Positif 1 & Positif 1 & $100 \%$ & \\
\hline 4 & & $1 \mathrm{~A} 4$ & Positif 1 & Positif 1 & Positif 1 & $100 \%$ & \\
\hline 5 & & $1 \mathrm{~A} 5$ & Positif 1 & Positif 1 & Positif 1 & $100 \%$ & \\
\hline 6 & \multirow{5}{*}{$50^{\circ} \mathrm{C}$} & 1B1 & Positif 1 & Positif 1 & Positif 1 & $100 \%$ & \\
\hline 7 & & 1B2 & Positif 1 & Positif 1 & Positif 1 & $100 \%$ & \\
\hline 8 & & $1 \mathrm{~B} 3$ & Positif 1 & Positif 1 & Positif 1 & $100 \%$ & \\
\hline 9 & & 1B4 & Positif 1 & Positif 1 & Positif 1 & $100 \%$ & \\
\hline 10 & & $1 \mathrm{~B} 5$ & Positif 1 & Positif 1 & Positif 1 & $100 \%$ & \\
\hline 11 & \multirow{5}{*}{$60^{\circ} \mathrm{C}$} & $1 \mathrm{C} 1$ & Positif 1 & Positif 1 & Positif 1 & $100 \%$ & \\
\hline 12 & & $1 \mathrm{C} 2$ & Positif 1 & Positif 1 & Positif 1 & $100 \%$ & \\
\hline 13 & & $1 \mathrm{C} 3$ & Positif 1 & Positif 1 & Positif 1 & $100 \%$ & \\
\hline 14 & & $1 \mathrm{C} 4$ & Positif 1 & Positif 1 & Positif 1 & $100 \%$ & \\
\hline 15 & & $1 \mathrm{C} 5$ & Positif 1 & Positif 1 & Positif 1 & $100 \%$ & \\
\hline 16 & \multirow{5}{*}{$70^{\circ} \mathrm{C}$} & 1D1 & Positif 1 & Positif 1 & Positif 1 & $100 \%$ & \\
\hline 17 & & 1D2 & Positif 1 & Positif 1 & Positif 1 & $100 \%$ & \\
\hline 18 & & 1D3 & Positif 1 & Positif 1 & Positif 1 & $100 \%$ & \\
\hline 19 & & 1D4 & Positif 1 & Positif 1 & Positif 1 & $100 \%$ & \\
\hline 20 & & 1D5 & Positif 1 & Positif 1 & Positif 1 & $100 \%$ & \\
\hline
\end{tabular}




\begin{tabular}{|c|c|c|c|c|c|c|}
\hline 21 & \multirow{5}{*}{$\begin{array}{l}\text { Suhu } \\
\text { kamar }\end{array}$} & $3 \mathrm{~A} 1$ & Positif 3 & Positif 3 & Positif 3 & $100 \%$ \\
\hline 22 & & $3 \mathrm{~A} 2$ & Positif 3 & Positif 3 & Positif 3 & $100 \%$ \\
\hline 23 & & $3 \mathrm{~A} 3$ & Positif 3 & Positif 3 & Positif 3 & $100 \%$ \\
\hline 24 & & $3 \mathrm{~A} 4$ & Positif 3 & Positif 3 & Positif 3 & $100 \%$ \\
\hline 25 & & $3 \mathrm{~A} 5$ & Positif 3 & Positif 3 & Positif 3 & $100 \%$ \\
\hline 26 & \multirow{5}{*}{$50^{\circ} \mathrm{C}$} & $3 \mathrm{~B} 1$ & Positif 3 & Positif 3 & Positif 3 & $100 \%$ \\
\hline 27 & & $3 \mathrm{~B} 2$ & Positif 3 & Positif 3 & Positif 3 & $100 \%$ \\
\hline 28 & & $3 \mathrm{~B} 3$ & Positif 3 & Positif 3 & Positif 3 & $100 \%$ \\
\hline 29 & & 3B4 & Positif 3 & Positif 3 & Positif 3 & $100 \%$ \\
\hline 30 & & $3 \mathrm{~B} 5$ & Positif 3 & Positif 3 & Positif 3 & $100 \%$ \\
\hline 31 & \multirow{5}{*}{$60^{\circ} \mathrm{C}$} & $3 \mathrm{C} 1$ & Positif 3 & Positif 3 & Positif 3 & $100 \%$ \\
\hline 32 & & $3 \mathrm{C} 2$ & Positif 3 & Positif 3 & Positif 3 & $100 \%$ \\
\hline 33 & & $3 \mathrm{C} 3$ & Positif 3 & Positif 3 & Positif 3 & $100 \%$ \\
\hline 34 & & $3 \mathrm{C} 4$ & Positif 3 & Positif 3 & Positif 3 & $100 \%$ \\
\hline 35 & & $3 \mathrm{C} 5$ & Positif 3 & Positif 3 & Positif 3 & $100 \%$ \\
\hline 36 & \multirow{5}{*}{$70^{\circ} \mathrm{C}$} & 3D1 & Positif 3 & Positif 3 & Positif 3 & $100 \%$ \\
\hline 37 & & $3 \mathrm{D} 2$ & Positif 3 & Positif 3 & Positif 3 & $100 \%$ \\
\hline 38 & & 3D3 & Positif 3 & Positif 3 & Positif 3 & $100 \%$ \\
\hline 39 & & $3 \mathrm{D} 4$ & Positif 3 & Positif 3 & Positif 3 & $100 \%$ \\
\hline 40 & & $3 \mathrm{D} 5$ & Positif 3 & Positif 3 & Positif 3 & $100 \%$ \\
\hline
\end{tabular}

\section{Simpulan}

Berdasarkan hasil pemeriksaan data pemeriksaan makroskopik, mikroskopik dan kultur maka didapatkan hasil penelitian sebagai berikut, 1)Tidak ada pengaruh pada pengeringan pada suhu kamar dan suhu inkubator. 2) Gambaran hasil preparat BTA pada pengeringan suhu $20^{\circ} \mathrm{C}$ (suhu kamar) dan suhu incubator $\left(50^{\circ} \mathrm{C}, 60^{\circ} \mathrm{C}\right.$ dan $\left.70^{\circ} \mathrm{C}\right)$, untuk sampel positif 1 didapatkan hasil $100 \%$ hasil pemeriksaan mikroskopik positif 1 , dan sampel positif 3 didapatkan hasil $100 \%$ pemeriksaan mikrskop positif 3 . 3)Gambaran stabilitas hasil preparat BTA pada pengeringan suhu $20^{\circ} \mathrm{C}$ (suhu kamar) dan suhu incubator $\left(50^{\circ} \mathrm{C}, 60^{\circ} \mathrm{C}\right.$ dan $\left.70^{\circ} \mathrm{C}\right)$ selama 3 minggu $100 \%$ hasilnya sama menunjukan preparat tersebut stabil.

\section{DAFTAR PUSTAKA}

1. Departemen Kesehatan Republik Indonesia. 2012. Pedoman Nasional Penanggulangan Tuberculosis Edisi 2. Jakarta. 
2. Direktorat Jenderal

Pemberantasan Penyakit

Menular Badan Penelitian Dan

Pengembangan Kesehatan. 2004.

Kajian Riset Operasional

Intensifikasi Pemberantasan

Penyakit Menular Tahun 1998/1999 - 2003. Jakarta.

3. Bonang, Gerard \&Enggar S. Koeswardono. 1982. Mikrobiologi Kedokteran untuk

5. Staf Pengajar FKUI. 1994. MikrobiologiKedokteran.

Jakarta: BinarupaAksara.

6. Moeliono AM. 1990. KamusBesar Bahasa Indonesia. BalaiPustaka Jakarta

7. Murray, Patrick R,. 2002. Manual of Clinical Microbiology (9th edition) Washington D.C: ASM PRESS.

8. http://2.bp.blogspot.com/ hNzXtP QyZcs/SxotBkNLnzI/AAAAAAA AAAU/tJgwBxgGnxc/s320/peny akit-tbc.jpg

9. Fujiki, Akiko. 2009. BTA Pelatihan Mikroskopis.

10. Lay, Bibiana. 1994. AnalisisMikroba di laboratorium. Jakarta: PT. Raja GrafindoPersada.

11. Laboratorium dan Klinik. Jakarta: PT. Gramedia. 